\title{
A LENTIDÃo NO PROCESSO DE IGUALDADE DE GÊNEROS NO MERCADO DE TRABALHO
}

\section{ARTIGO DE REVISÃO}

PARDIM, Larissa Procópio ${ }^{1}$

SCATOLIN, Henrique Guilherme ${ }^{2}$

PARDIM, Larissa Procópio. SCATOLIN, Henrique Guilherme. A lentidão no processo de igualdade de gêneros no Mercado de Trabalho. Revista Científica Multidisciplinar Núcleo do Conhecimento. Ano 05, Ed. 03, Vol. 09, pp. 18-30. Março de 2020. ISSN: 2448-0959, Link de acesso: https://www.nucleodoconhecimento.com.br/psicologia/lentidao-no-processo

\section{RESUMO}

Ao longo da evolução das relações de trabalho é notável a alteração significativa do papel da mulher no mercado, seja ele formal ou informal. Atualmente, a presença da figura feminina no ambiente de trabalho é de suma importância e o reconhecimento deste fato é o que tem levado a mulher à conquista de seu espaço, mesmo que isso seja de forma gradativa. Embora o número de mulheres nas empresas tenha crescido em grande escala desde o início da inserção da mulher no mercado, no século XIX após a revolução industrial, ainda se enfrenta obstáculos e paradigmas que serão ressaltados neste texto. Este artigo tem por objetivo apresentar a realidade do mercado de trabalho feminino no seu início, passando pelos anos 90 e, por último, destacando situações atuais. Através dessa linha de evolução será identificado se as mulheres, de fato, alcançaram os homens no que se refere à faixa salarial,

\footnotetext{
${ }_{1}^{1}$ Pós-graduada em Psicologia Organizacional e do Trabalho pela FHO - Uniararas, tecnóloga em Recursos Humanos.

2 Doutor em Psicologia.
} 
oportunidade de cargos de chefia e espaço em todas as áreas de ocupações e também o tempo que essa conquista levou a acontecer.

Palavras-chave: Mulher, mundo do trabalho, trabalho feminino.

\section{INTRODUÇÃO}

Diante de muitas transformações no mercado de trabalho, demandadas pela revolução industrial, passando pela forte globalização e, mais recente, a era da informatização, percebe-se pontos em destaque dentre todas as transformações até então ocorridas. Como um destes destaques tem-se a imagem da mulher no trabalho, tanto no trabalho formal quanto no informal. Para tais conquistas, inúmeros obstáculos e paradigmas arraigados na sociedade dificultaram este processo de inserção e reconhecimento da mulher trabalhadora.

Neste artigo, inicialmente, será apresentado o ingresso da mulher no mercado de trabalho que se deu no século XIX, desencadeado pela revolução industrial e pela necessidade de redução dos gastos dos empregadores com seus trabalhadores. Em um primeiro momento será possível verificar a forte diferença existente entre as condições do trabalhador e da trabalhadora, no que diz respeito à carga horária, oportunidades de ascensão profissional e equiparação salarial, entre outros aspectos que serão expostos.

Em meados dos anos 90, mudanças significativas acontecem no cenário do mercado de trabalho feminino; mas a busca constante de reconhecimento igualitário ao do homem trabalhador não se findou; pois o objetivo não foi alcançado. Neste ponto percebe-se que décadas após a inserção da mulher no mercado de trabalho, a sociedade ainda delimita o espaço a ser ocupado pela mulher, constatando o vagaroso processo de igualdade de gêneros, estes definidos por Castilho (2008) como a categoria usada para fazer a relação entre masculino e feminino, considerando diferenças biológicas e reconhecendo a desigualdade entre os sexos. Os gêneros são instrumentos de compreensão das relações sociais entre homens e mulheres. Mougeolle (2015) comenta sobre gênero fazendo relação com aspectos sociais e 
culturais, considerando este conceito para falar das desigualdades, hierarquias, dominação masculina, entre outros assuntos.

Este artigo visa contribuir com estudos relacionados ao homem e à mulher no mercado de trabalho, exibindo o moroso desenvolvimento do processo enfrentado pela mulher para atingir a igualdade de gêneros, tendo em vista a atual posição da mulher na sociedade e os objetivos alcançados, fazendo um comparativo com o início da participação da mulher trabalhadora e com outros pontos da história.

O presente estudo partiu de uma indagação sobre a relação entre o discurso social e organizacional sobre a igualdade de gêneros supostamente presente no mercado de trabalho e em outros âmbitos sociais e, de fato, a prática do que permite considerar este discurso como conduta real exercida pela sociedade em geral e, principalmente, pelos empregadores.

\section{METODOLOGIA}

Para o desenvolvimento deste artigo realizou-se uma pesquisa de revisão de literatura no período de julho a setembro de 2017. De acordo com Mancini e Sampaio:

Revisões da literatura são caracterizadas pela análise e pela síntese da informação disponibilizada por todos os estudos relevantes publicados sobre um determinado tema, de forma a resumir o corpo de conhecimento existente e levar a concluir sobre o assunto de interesse. Existem diversos tipos de estudos de revisão e cada um deles segue uma metodologia específica. (MANCINI; SAMPAIO, 2006, p. 1)

Utilizou-se uma metodologia descritiva a fim de expor as informações históricas sobre o trabalho da mulher, passando por alguns pontos importantes desde o início de seus registros e fazendo uma análise comparativa sobre as etapas desse processo de fortalecimento da imagem da mulher no mercado. A abordagem da pesquisa é caracterizada como mista (qualitativa e também quantitativa); pois relaciona dados 
narrativos bem como dados numéricos para descrever as situações e os cenários de cada época referida.

Foram realizadas pesquisas nas ferramentas de pesquisa acadêmica online Google Acadêmico e Scielo, livros na biblioteca do Centro Universitário Hermínio Ometto e dados de pesquisas confeccionadas pelo IBGE. Utilizou-se para as pesquisas as seguintes palavras chaves: mulher, mercado de trabalho e trabalho feminino. Dentre as encontradas, priorizou-se produções que possuem mais coerência com o tema sugerido desta pesquisa, inclusive publicações mais antigas pois se trata de um artigo com uma determinada linha histórica.

\section{FUNDAMENTAÇÃO TEÓRICA}

Partindo da visão do mundo globalizado, da competitividade e das diversas formas de trabalho presentes no cenário atual, é imediata a identificação do papel distinto da mulher trabalhadora, seja dentro ou fora das organizações. Entretanto, em seu ingresso ao mercado de trabalho, a mulher enfrentou inúmeras adversidades que prejudicaram seu desenvolvimento profissional. Prosbt (2015) afirma que as primeiras convenções ditavam o homem como trabalhador único e responsável pela renda familiar e a mulher não deveria exercer qualquer atividade que caracterizasse este papel. É no século XIX, a partir da Revolução Industrial, que a mulher inicia sua trajetória de ingresso ao trabalho como classe efetivamente ativa, momento em que houve a necessidade de complementar a renda familiar, o que ocasionou a inserção das mulheres no mercado remunerado, sendo obrigadas a desempenhar atividades dolorosas e mal remuneradas (GIRÃO, 2001 apud AMARAL, 2012).

Houve, ainda no século XIX, o princípio da presença da mulher em vários setores da indústria. Conforme Bossa (1998), o desenvolvimento industrial foi o que possibilitou o grande ganho de espaço da atividade feminina; pois com o surgimento de novas profissões, iniciou-se a disputa sexual do trabalho. Entretanto, a mulher era caracterizada como mão-de-obra barata e menos produtiva que a do homem devido à necessidade de submeter-se a diversas funções. 
Não havia proteção à mulher sobre direitos trabalhistas, como alega Bossa:

O Estado não interferia nas relações jurídicas de trabalho, permitindo toda a sorte de exploração. As mulheres eram remuneradas ao livre arbítrio dos patrões, eram desprezadas e colocadas em postos inferiores, com menores salários; as menos instruídas eram consideradas aptas somente em certos períodos de sua vida, ou seja, quando jovens e solteiras, exercendo apenas um tipo de atividade sem qualquer profissionalização. (BOSSA, 1998, p. 3)

Entretanto, a crescente presença da mulher no mercado fez com que seus direitos fossem adquiridos, mesmo que lentamente. O Decreto № 21.417 de 17 de maio de 1932 referiu-se à mulher trabalhadora, assegurando algumas medidas de proteção: o trabalho noturno foi proibido, houve proibição também do trabalho em mineradoras, em subsolo, pedreiras e obras públicas e nos serviços considerados insalubres e perigosos; estabeleceu descanso antes e depois do parto; em locais de trabalho que tivessem 30 mulheres ou mais com idade acima de 16 anos e deveria haver espaço para a amamentação (BOSSA, 1998).

A maioria destes direitos (que, em grande parte, somente classificaram a mulher como ser frágil) ficaram apenas na teoria, uma vez que, em confronto com a realidade da prática dos empregadores, havia divergência no que deveria ser cumprido. De acordo com Paoli (1985 apud AMARAL, 2012), mesmo que no discurso os empregadores concordassem com esses direitos, na prática eles eram violados. Comprovou-se isto através de movimentos das operárias que aconteceram logo após a promulgação desta Lei, constatando a falta de cumprimento desta regulamentação.

Décadas após o surgimento da mulher no mercado, nos anos 70, um dos maiores conflitos na vida da mulher empregada foi o de deixar de dedicar-se inteiramente ao trabalho doméstico (casa, marido e filhos) e dirigir-se ao trabalho público. Reduziu-se significativamente a taxa de fecundidade através de métodos contraceptivos adotados nesta época, facilitando a ampliação da atividade feminina por estarem mais disponíveis ao trabalho; mas o grupo e estrutura familiar são fatores determinantes no 
momento da escolha da mulher de ingressar ou de permanecer no mercado de trabalho; pois ainda é seu o papel de responsável pela organização da família (BRUSCHINI; LOMBARDI, 1996).

De acordo com Bruschini e Lombardi (1996), no que diz respeito à escolaridade, a maior parte das mulheres que ingressaram ao mercado de trabalho brasileiro é composta pela população escolarizada e de classe média. A facilidade de acesso às universidades para mulheres desta camada social existente nos anos 90 transformou ainda mais os padrões de comportamento e valores referentes à mulher. Neste momento, as mulheres encontram-se muito mais instruídas, conforme Bruschini e Lombardi (2002), há predominância feminina no ensino médio: entre o total dos alunos do ensino médio, $55 \%$ deles eram mulheres, e $54,2 \%$ no ensino superior. No entanto, a mulher mais escolarizada e com mais independência não alcança os índices do homem no mercado de trabalho. Mesmo com jornadas de trabalho e vínculos empregatícios similares, a desigualdade permanece no que é alusivo à remuneração: o salário da mulher é inferior ao do homem (BRUSCHINI; LOMBARDI, 2002).

No início da década de 90 os registros apontam que não só as mulheres mais jovens estavam adentrando em massa ao mercado, mas também grande número das mulheres trabalhadoras entre 30 e 39 anos foi registrado, representando um cenário onde a mulher casada e com filhos estava presente no trabalho público (LOMBARBI; BRUSCHINI, 1996). De acordo com dados das PNADs (Pesquisa Nacional por Amostra de Domicílio), em 1993 Bruschini e Lombardi (1996) confirmaram o crescimento do número de trabalhadoras no Brasil, tendo $39,6 \%$ do total de trabalhadores como volume feminino. Entretanto, foi nesta época que a terceirização do trabalho teve grande força e a mulher, por ser a principal ocupante destes cargos, foi o que possibilitou a permanência da trabalhadora no mercado, mesmo em período de crise.

O destaque do trabalho feminino na década de 90 era o trabalho por conta própria e no comércio de mercadorias (através do início do comércio ambulante). Essa expansão tornou muitos desses negócios tão rentáveis a ponto de serem a principal renda familiar. Abriu então um espaço de trabalho para a mulher da terceira idade e 
as com baixa instrução devido à falta de exigência de formação e competências nessas categorias. As domésticas (com ou sem carteira) correspondiam a mais da metade do total da ampliação dos empregos femininos (WAJNMAN; QUEIROZ; LIBERATO, 1998).

Apesar da crescente expansão do trabalho feminino em diversos setores, a diferença entre o número de cargos ocupados por homens e mulheres é muito notável. Em 1995, do total de trabalhadores e trabalhadoras que exerciam atividades não-agrícolas, apenas 40\% eram mulheres (WAJNMAN; QUEIROZ; LIBERATO, 1998).

Em somatória à diferença no número de mulheres e homens ocupando os cargos de trabalho, outras desigualdades também eram existentes ainda na década de 90. Conforme Bossa (1998) existe sim um avanço da atividade feminina; mas no que se refere à igualdade de direitos e salários entre os gêneros, não é possível identificar o mesmo avanço. As mulheres brasileiras têm seus salários $40 \%$ mais baixos que a dos homens que exercem a mesma função. Com o desenvolvimento tecnológico e a entrada da mulher também no mundo dos negócios, esperava-se um desenvolvimento da faixa salarial feminina na mesma proporção, mas isso não ocorreu.

Posteriormente, no século XXI, entre os anos de 2001 e 2009 ainda não era afirmada a igualdade entre os gêneros no mercado de trabalho. Para Mattos (2009), ainda neste contexto, homens e mulheres não conseguem a mesma participação nas organizações. A mulher está em constante situação inferior à do homem e este ocupa a maioria dos cargos de diretoria que envolvem maior poder de decisão. Assim, a ocupação feminina nos cargos de comando vai acontecendo de maneira muito lenta.

O mesmo ponto de desigualdade na ocupação dos cargos é relato por Fontoura e Gonzalez:

Apesar do crescimento contínuo, a proporção de mulheres trabalhando ou à procura de trabalho no Brasil ainda é bastante inferior à dos homens, que tem se mantido estável ao longo dos últimos anos. Com isso, em 2008 , enquanto $57,6 \%$ das brasileiras participavam do mercado 
de trabalho, $80,5 \%$ dos homens estavam na mesma situação. (FONTOURA; GONZALEZ, 2009, p.21)

Fontoura e Gonzalez (2009) apontam que a porcentagem das mulheres brasileiras desempregadas, entre as que eram consideradas economicamente ativas em 2008, era de $9,6 \%$, enquanto a dos homens era de $5,2 \%$, traduzindo a imagem de que a mulher passa por obstáculos para ingressar ao mercado e muitos outros para conseguir uma colocação dentro dele.

Ao comparar as médias salarias do trabalhador e trabalhadora no ano de 2008, Fontoura e Gonzalez (2009) relataram que as desigualdades são claramente existentes: homens ganhando aproximadamente $35 \%$ a mais que as mulheres. Essa diferença pode ser identificada nas áreas rurais, entre trabalhadores com idade avançada e nas camadas mais pobres.

Em um questionário sobre mulher intitulado "Mulher no Mercado de Trabalho: Perguntas e Respostas", o IBGE (Instituto Brasileiro de Geografia e Estatística) levantou dados comparativos entre homens e mulheres no mercado de trabalho no ano de 2009. Conforme gráficos abaixo, pode-se ressaltar a desigualdade no presente momento:

Figura 1: Dados comparativos entre homens e mulheres, com carteiras assinadas, de 2009.

Proporção de pessoas ocupadas com carteira de trabalho assinada por sexo, segundo os grupamentos de atividade $-2009^{*}$

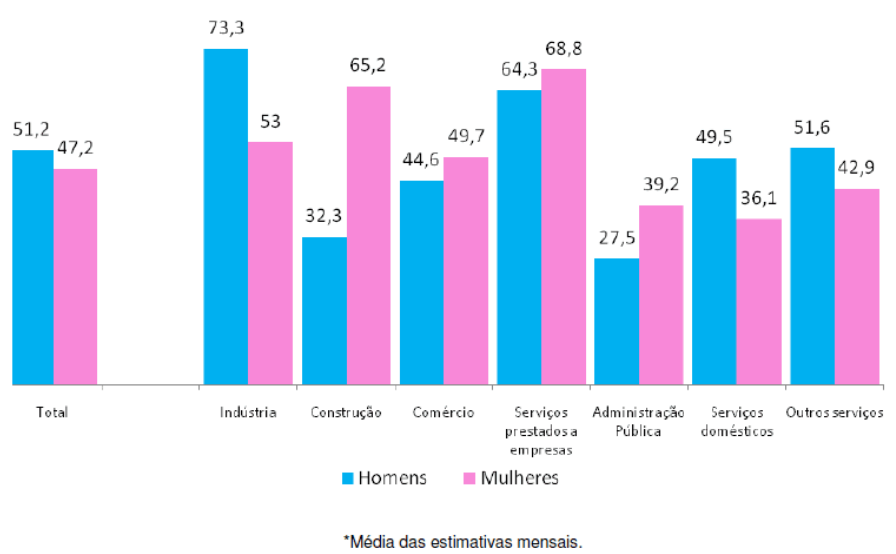


Fonte: IBGE, 2010.

Figura 2: Rendimento médio masculino, por escolaridade, de 2009.

Rendimento médio habitual da população ocupada masculina, por escolaridade, segundo grupamentos de atividade $-2009^{*}$.

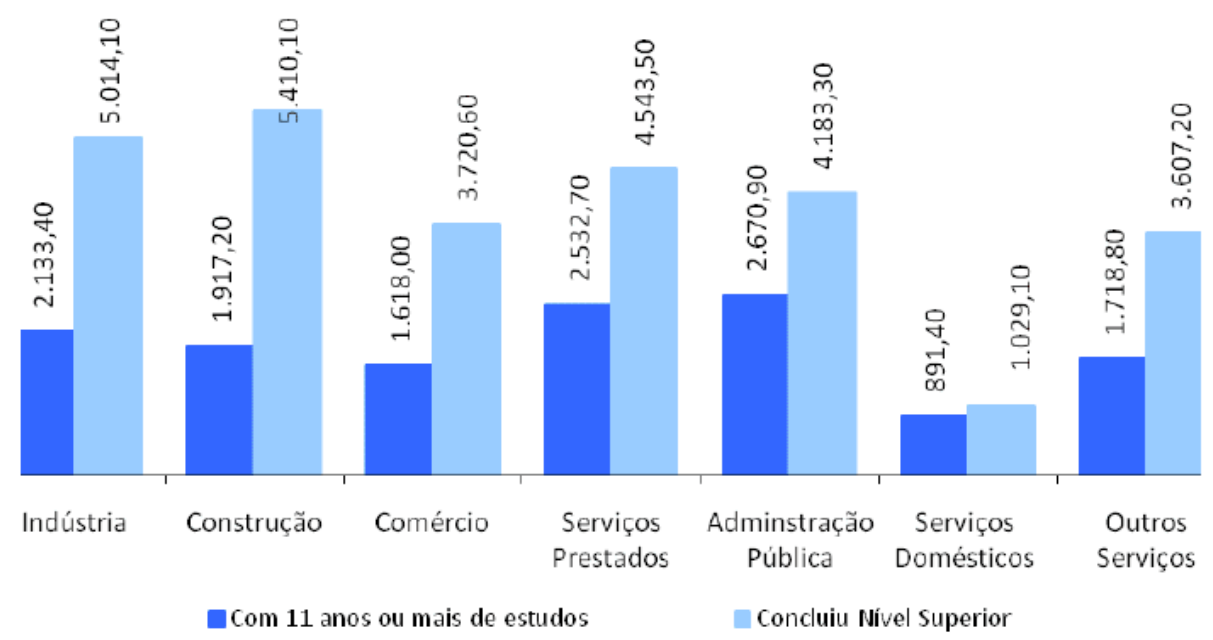

Fonte: IBGE, 2010.

Figura 3: Rendimento médio feminino, por escolaridade, do ano de 2009.

Rendimento médio habitual da população ocupada feminina, por escolaridade, segundo os grupamentos de atividade $-2009^{\star}$.

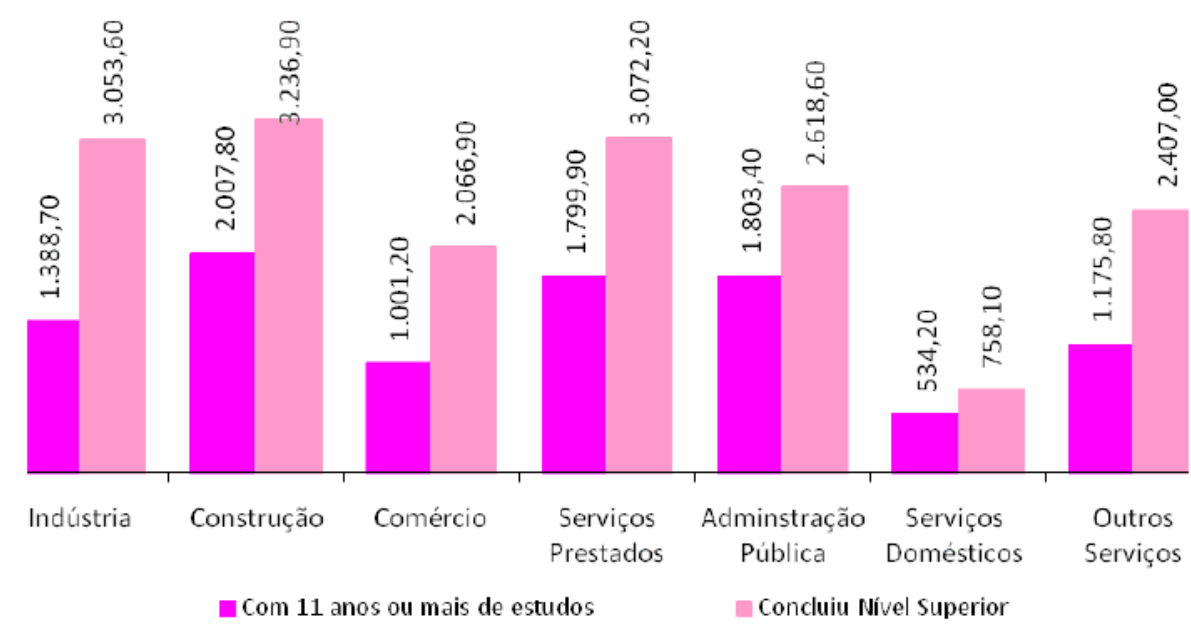

Fonte: IBGE, 2010. 
A média anual da remuneração das mulheres em 2009 foi $27,7 \%$ inferior à dos homens, mesmo considerando grupos mais similares, ou seja, mesma escolaridade e exercendo a mesma atividade. Assim, permanece a diferença de rendimentos entre os gêneros, tendo a população masculina a maior porcentagem (IBGE, 2010).

As mulheres, ainda de forma muito intensa, trabalham nas organizações caracterizadas femininas, porque se sentem acuadas pela improvável contratação nas organizações que são "tipicamente masculinas". Em contrapartida, o homem facilmente tem a oportunidade de se inserir nas organizações "tipicamente femininas" como instituições educacionais e assistência social, mantendo assim o ciclo da permanência da "masculinização" em determinadas categorias visto que, a diversidade de gêneros não assume presença ampla e sólida capaz de atingir a igualdade neste cenário (MATTOS, 2009).

\section{APRESENTAÇÃO E ANÁLISE DOS RESULTADOS}

Esta pesquisa identificou as diversas etapas que a mulher enfrenta para a possível conquista da igualdade de gêneros no mercado trabalho. Através da análise dessas etapas decorridas por décadas (desde o ingresso da mulher no mercado), constatouse que grandes passos se deram ao longo da história, porém, este processo ocorre de forma lenta e árdua (FONTOURA e GONZALEZ, 2009).

O papel da mulher como única responsável pela educação dos filhos, tarefas domésticas e organização da família vem sendo dissipado, mas a sociedade e a própria mulher ainda depositam a culpabilidade de problemas e conflitos internos relacionados à estrutura familiar e à imagem da mulher como protetora e cuidadora deste ambiente (WAJNMAN; QUEIROZ; LIBERATO, 1998).

Os números registrados concernentes à população feminina em torno do mercado de trabalho, mesmo em pesquisas realizadas em períodos mais recentes, persistem em ser inferiores ao da população masculina, principalmente no que se refere à empregabilidade, faixa salarial e estabilidade no mercado (FONTOURA e GONZALEZ, 2009). 
Relacionando os avanços registrados com as estruturas sociais difíceis de serem rompidas, constata-se que diferenças marcantes entre os gêneros ainda estão presentes no ambiente de trabalho, seja no mercado formal ou informal. A mulher precisa caminhar incansavelmente em busca da sua igualdade, da quebra de barreiras sociais e da conquista de melhor colocação nas organizações a fim de alcançarem reconhecimento e, sobretudo, igualdade salarial, fator de extrema relevância nesta pesquisa (BRUSCHINI; LOMBARDI, 2002). Essas informações nos levam a compreender a forte questão cultural que distingue os gêneros não só no âmbito do trabalho, mas em diversos outros ambientes que registram o preconceito $\mathrm{e}$ a desigualdade que marca desventuradamente a sociedade brasileira.

\section{CONSIDERAÇÕES FINAIS}

Muito foi descoberto e adquirido através desta pesquisa de revisão de literatura com ricas contribuições dos autores citados anteriormente, compartilhando dados históricos que trouxeram reflexões sobre o cotidiano e a maneira como a mulher é vista nos diversos ambientes que estão colocadas. Entretanto, mesmo com muitas buscas, houve certa dificuldade em encontrar publicações de diferentes autores que dissertassem sobre o tema mulher e trabalho, principalmente no início do trabalho da mulher até os anos 80. A maioria das publicações encontradas foram das mesmas autoras, ou então, artigos sobre mulheres e mercado de trabalho que as referenciaram a partir da década de 90 .

Assim, este trabalho (de revisão de literatura) traçou uma linha cronológica do ingresso da mulher ao trabalho no século XIX, com alguns comentários sobre os anos 70 , frisando a relação mulher e trabalho a partir da década de 90 , trazendo informações da empregabilidade feminina das duas últimas décadas. Faculta-se, então, a oportunidade de maiores pesquisas sobre o tema e possibilita-se a continuidade desta linha de pesquisa com dados mais recentes em futuras pesquisas acerca desta problemática. 


\title{
REFERÊNCIAS
}

\begin{abstract}
AMARAL, G. A. AMARAL, G. A. Os desafios da inserção da mulher no mercado de trabalho. Jataí: Revista Eletrônica Itinerarius Reflectionis, v. 2, 2012. Semestral. Disponível em: <https://www.revistas.ufg.br/rir/article/view/22336/19243>. Acesso em: 08 jun. 2017.
\end{abstract}

BOSSA, S. Direito do Trabalho da Mulher: No contexto social brasileiro e medidas antidiscriminatórias. São Paulo: Oliveira Mendes, 1998. 72 p.

BRUSCHINI, C.; LOMBARDI, M. R. O trabalho da mulher brasileira dos primeiros anos da década de noventa. In: ENCONTRO NACIONAL DE ESTUDOS POPULACIONAIS, 10., 1996, Belo Horizonte. Anais...Belo Horizonte: s.n., 1996. p. 483-516.

Disponível

em: <http://www.abep.org.br/publicacoes/index.php/anais/article/view/722/700>. Acesso em: 10 jul. 2017.

BRUSCHINI, C; LOMBARDI, M. R. Trabalhadoras brasileiras dos anos 90: mais numerosas, mais velha, mais instruídas. Ensaio: Revistas eletrônicas FEE, Rio Grande do Sul, v. 2, p. 95-105, 2002. Trimestral. Disponível em: <Revistas Eletrônicas FEE>. Acesso em: 01 set. 2017.

CASTILHO, E. W. V. O que é gênero. 2008. Disponível em: <http://pfdc.pgr.mpf.mp.br/pfdc/informacao-e-comunicacao/eventos/mulher/dia-damulher/verbet>. Acesso em: 11 set. 2017.

FONTOURA, N. de Oliveira; GONZALEZ, R. (Org.). Mercado de Trabalho: Conjuntura e Análise: Aumento da participação de mulheres no mercado de trabalho: mudança ou reprodução da desigualdade?. Brasil: s.n., 2009. 26 p. Detentor dos direitos autorais: Instituto de Pesquisa Econômica Aplicada (Ipea). Disponível em: <http://repositorio.ipea.gov.br/handle/11058/4056>. Acesso em: 15 ago. 2017.

MANCINI, M. C.; SAMPAIO, R. F. Quando o objeto de estudo é a literatura: estudos de revisão.2006. Disponível em: 
$<$ http://www.scielo.br/scielo.php?script=sci_arttext\&pid=S1413$35552006000400001 \&$ Ing=pt\&nrm=iso\&tlng=pt>. Acesso em: 15 set. 2017.

MATTOS, A. H. G. A ocupação feminina no mercado de trabalho: desafios para a gestão contemporânea das organizações. 2009. Disponível em: <http://seer4.fapa.com.br/index.php/arquivo/article/view/4/2>. Acesso em: 19 ago. 2017.

MOUGEOLLE, L. 0 conceito de gênero. 2015. Disponível em: <http://www.sociologia.com.br/o-conceito-de-genero/>. Acesso em: 14 set. 2017.

PESQUISA MENSAL DE EMPREGo - PME. Mulher no mercado de trabalho: perguntas e respostas. Brasil: IBGE, 2010. Disponível em: $<$ https://ww2.ibge.gov.br/home/estatistica/indicadores/trabalhoerendimento/pme_nov a/Mulher_Mercado_Trabalho_Perg_Resp.pdf>. Acesso em: 07 set. 2017.

PROBST, E. R. A Evolução da Mulher no Mercado de Trabalho. 2015. Disponível

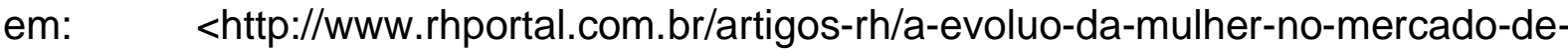
trabalho/>. Acesso em: 30 jun. 2017.

WAJNMAN, S.; QUEIROZ, B. L.; LIBERATO, V. C. O crescimento da atividade feminina nos anos noventa no Brasil. In: ENCONTRO NACIONAL DE ESTUDOS POPULACIONAIS, 11., 1998, Caxambu. Anais...Caxambu: s.n., 1998. p. 2429-2454. Disponível em: <http://www.abep.org.br/publicacoes/index.php/anais/article/view/936/901>. Acesso em: 10 jul. 2017.

Enviado: Setembro, 2019

Aprovado: Março, 2020. 